\title{
Article \\ Role of Antimicrobial Susceptibility Testing before First-Line Treatment Containing Clarithromycin for Helicobacter pylori Eradication in the Clinical Setting
}

\author{
Seokin Kang ${ }^{1,+}$, , Yuri Kim ${ }^{1,+}$, Ji Yong Ahn ${ }^{1, *}$, Hwoon-Yong Jung ${ }^{1, *} \mathbb{D}$, Nayoung Kim ${ }^{2}$, Hee Kyong Na ${ }^{1}$, \\ Jeong Hoon Lee ${ }^{1}$, Kee Wook Jung ${ }^{1}$, Do Hoon Kim ${ }^{1}$, Kee Don Choi ${ }^{1}$, Ho June Song ${ }^{1}$ and Gin Hyug Lee ${ }^{1}$ \\ 1 Asan Medical Center, Department of Gastroenterology, University of Ulsan College of Medicine, \\ Seoul 05505, Korea; SeokinKang.MD@gmail.com (S.K.); arcoiris0209@gmail.com (Y.K.); \\ hkna77@naver.com (H.K.N.); jhlee.gi@amc.seoul.kr (J.H.L.); jung.keewook30@gmail.com (K.W.J.); \\ dohoon.md@gmail.com (D.H.K.); keedon@amc.seoul.kr (K.D.C.); hjsong@amc.seoul.kr (H.J.S.); \\ jhlee409@amc.seoul.kr (G.H.L.) \\ 2 Asan Medical Center, Department of Clinical Epidemiology and Biostatistics, University of Ulsan College of \\ Medicine, Seoul 05505, Korea; nyny0803@amc.seoul.kr \\ * Correspondence: ji110@hanmail.net (J.Y.A.); hyjung@amc.seoul.kr (H.-Y.J.) \\ + Seokin Kang and Yuri Kim contributed equally as first authors.
}

\section{check for} updates

Citation: Kang, S.; Kim, Y.; Ahn, J.Y.; Jung, H.-Y.; Kim, N.; Na, H.K.; Lee, J.H.; Jung, K.W.; Kim, D.H.; Choi, K.D.; et al. Role of Antimicrobial Susceptibility Testing before First-Line Treatment Containing Clarithromycin for Helicobacter pylori Eradication in the Clinical Setting. Antibiotics 2021, 10, 214. https:// doi.org/10.3390/antibiotics10020214

Academic Editor: Giulia Bernardini

Received: 31 January 2021

Accepted: 18 February 2021

Published: 21 February 2021

Publisher's Note: MDPI stays neutral with regard to jurisdictional claims in published maps and institutional affiliations.

Copyright: (c) 2021 by the authors. Licensee MDPI, Basel, Switzerland. This article is an open access article distributed under the terms and conditions of the Creative Commons Attribution (CC BY) license (https:/ / creativecommons.org/licenses/by/ $4.0 /)$.

\begin{abstract}
Background: Checking Helicobacter pylori susceptibility tests in the clinical setting before firstline treatment is considered difficult. We compared susceptibility-guided therapy (SGT) with empirical therapy (ET) as a first-line treatment containing clarithromycin and investigated the eradication rate using antimicrobial susceptibility testing (AST). Methods: 257 patients with $H$. pylori infection, with AST, performed before the eradication of clarithromycin-containing regimens were enrolled and divided into two groups: the SGT and ET groups. Results: Eradication rates in the SGT and ET groups were $85.4 \%$ and $58.4 \%(P<0.01)$, respectively. In triple therapy $(\mathrm{TT})$, eradication rates of the SGT and ET groups were $85.1 \%$ and $56.6 \%(P<0.01)$, respectively. In sequential therapy (SET), eradication rates of the SGT and ET groups were $86.2 \%$ and $65.6 \%(P=0.06)$, respectively. According to AST, TT had an eradication rate of $84.6 \%$ with strains susceptible to clarithromycin and amoxicillin and $11.1 \%$ with strains resistant to both. SET had an eradication rate of $89.5 \%$ with strains susceptible to clarithromycin, amoxicillin, and metronidazole, whereas it was $0 \%$ with strains resistant to clarithromycin and metronidazole. Conclusions: SGT as first-line treatment improved eradication rates of TT and SET by $28.5(P<0.01)$ and $20.6(P=0.06)$ percent points, respectively, compared with ET.
\end{abstract}

Keywords: Helicobacter pylori; Helicobacter infection; clarithromycin; microbial sensitivity tests; microbial drug resistance

\section{Introduction}

Helicobacter pylori (H. pylori) is one of the most common pathogens causing chronic infection in humans and infecting approximately 4.4 billion people globally [1]. In Korea, the prevalence rate of $H$. pylori infection is $51.0 \%$, according to a Korean nationwide study [2]. $H$. pylori can survive in the acidic environment of the stomach and is a major risk factor for gastritis, peptic ulcer disease, and gastric cancer. It has also been accepted as a risk factor for gastric mucosa-associated lymphoid tissue lymphoma and extragastrointestinal diseases, including immunologic impairment and cardiovascular diseases [3-6]. Eradication of $H$. pylori may decrease the incidence rate of such diseases and is important in promoting public health. H. pylori is in the replicative phase at neutral $\mathrm{pH}(6-7)$, which is susceptible to antibiotics and is in the coccoid form at acid $\mathrm{pH}(3-6)$, which is resistant to antibiotics [7-10]. Thus, proton pump inhibitors play an important role in eradicating H. pylori by increasing intragastric $\mathrm{pH}$. Clarithromycin is bacteriostatic and binds to the 
$50 \mathrm{~S}$ ribosomal subunit to block protein synthesis of $H$. pylori. Metronidazole is bactericidal and enters membranes, leading to the production of toxic metabolites, such as free radicals within H. pylori. Amoxicillin is bactericidal and inhibits the synthesis of $H$. pylori cell walls.

The Korean Society of Gastroenterology guideline recommends clarithromycin triple therapy (TT) regimen as a first-line treatment for $H$. pylori infection [11] because clarithromycin is the core antibiotic for eradication H. pylori [12,13]. However, the efficacy of clarithromycin-containing regimens has decreased due to an increase in clarithromycin resistance rates [14-17]. The American College of Gastroenterology guideline suggests not only clarithromycin TT regimen as a first-line treatment but also other numerous regimens, including bismuth quadruple therapy, concomitant therapy, sequential therapy (SET), hybrid therapy, levofloxacin triple therapy, and fluoroquinolone sequential therapy regimens [6]. Maastricht guidance document recommends performing clarithromycin susceptibility testing before the initiation of clarithromycin-based treatment where clarithromycin resistance is more than $15 \%$ [18].

It is difficult to check the results of $H$. pylori susceptibility testing before the initiation of eradication therapy in the clinical setting. First, failure of $H$. pylori culture is not uncommon $[19,20]$. Second, after $H$. pylori are cultured, it usually takes 10 days to even two weeks to obtain the results of susceptibility testing [21]. In case a patient visits the clinic before the results are reported, a physician cannot start eradication therapy based on antimicrobial susceptibility and should provide empirical therapy.

In this study, by retrospectively analyzing patient medical records, we compared susceptibility-guided therapy with empirical therapy as a first-line treatment containing clarithromycin for $H$. pylori eradication and investigated the eradication rate according to antimicrobial susceptibility testing.

\section{Materials and Methods}

\subsection{Patients}

From September 2008 to December 2019, a total of 634 patients were diagnosed with $H$. pylori infection and underwent upper gastrointestinal endoscopies to obtain gastric mucosal tissues cultured for antimicrobial susceptibility tests before the initiation of eradication therapy at the Asan Medical Center, Seoul, Korea. In total, 377 patients were excluded (141 did not undergo H. pylori eradication therapy, 121 received H. pylori eradication therapy that did not contain clarithromycin, 88 became lost to follow-up after eradication therapy, and 27 did not perform urea breath tests after completing therapy). Finally, 257 patients who received clarithromycin-containing regimens and underwent urea breath tests for confirming eradication at least four weeks after completing therapy were included in the study. They were divided into two groups: the susceptibility-guided therapy group $(n=103)$, who were treated based on the results of susceptibility testing (for example, when the strains were resistant to clarithromycin, the patient did not receive clarithromycin-containing regimen), and the empirical therapy group $(n=154)$, who were treated before the results of the susceptibility test were reported (Figure 1).

TT consisted of twice-daily amoxicillin $(1000 \mathrm{mg})$, clarithromycin $(500 \mathrm{mg})$, and a standard dose of proton pump inhibitor for one or two weeks. SET for 10 days consisted of twice-daily amoxicillin (1000 $\mathrm{mg}$ ) and a standard dose of proton pump inhibitor for five days, followed by twice-daily clarithromycin $(500 \mathrm{mg})$, metronidazole $(500 \mathrm{mg})$, and a standard dose of proton pump inhibitor for another five days.

Ethical approval for this study was obtained from the Institutional Review Board of the Asan Medical Center. (IRB number; 2020-0518). 


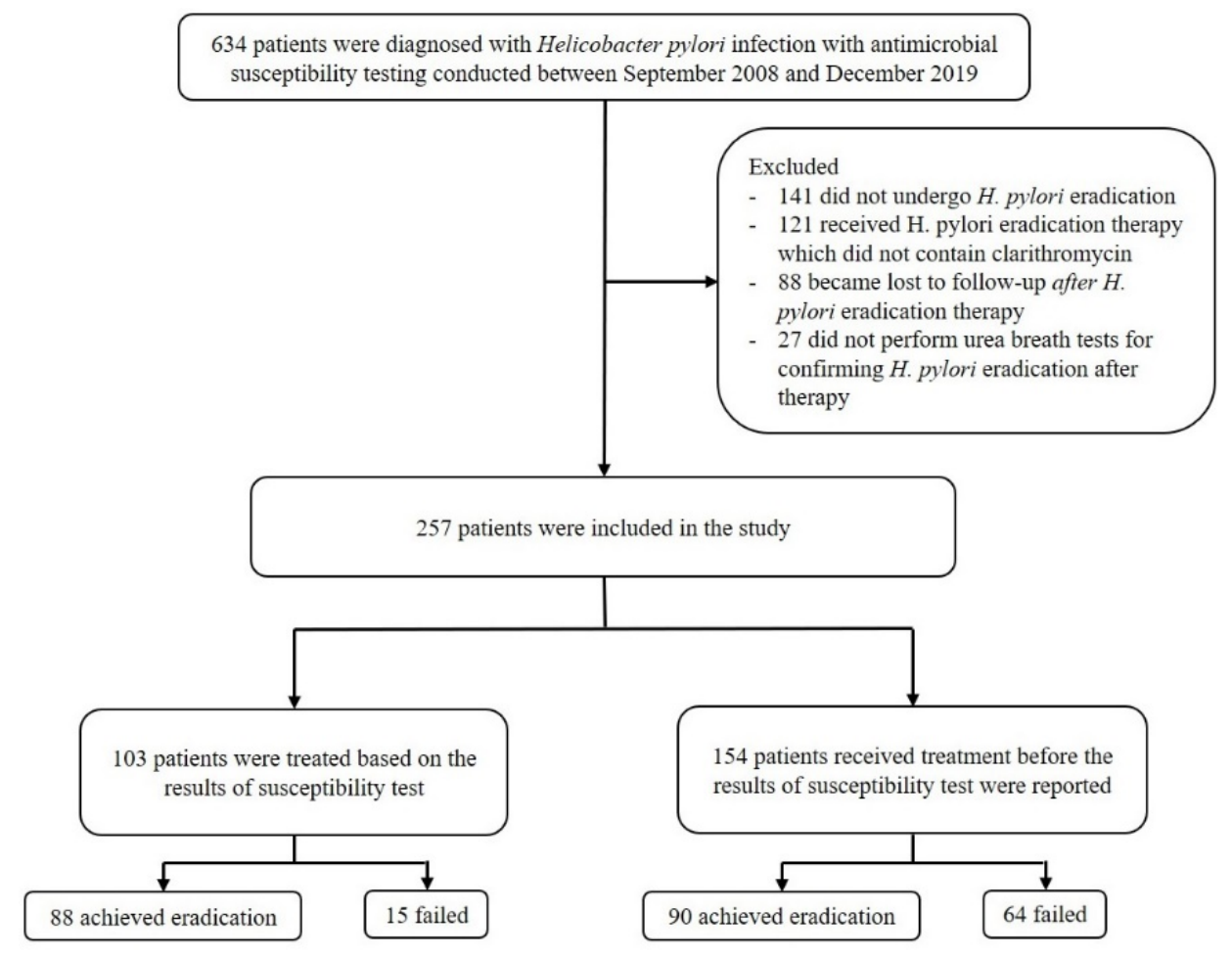

Figure 1. Flowchart of the process of patient enrollment.

\subsection{Isolation and Culture of H. pylori}

The culture medium plates were Brucella broth agar that was supplemented with $5 \%$ sheep blood (Becton, Dickinson, NJ, USA), vancomycin (10 $\mathrm{gg} / \mathrm{mL})$, trimethoprim $(5 \mu \mathrm{g} / \mathrm{mL})$, amphotericin B $(5 \mu \mathrm{g} / \mathrm{mL})$, and polymyxin B (2.5 IU) (Sigma-Aldrich, Darmstadt, Germany). The plates were incubated under $37^{\circ} \mathrm{C}$ in microaerophilic conditions for three to seven days (Forma Series II Water Jacketed $\mathrm{CO}_{2}$ Incubator Model 3131, Thermo Fisher Scientific, Waltham, MA, USA). H. pylori colonies were confirmed by gram staining, a positive reaction with urease, catalase, and oxidase tests, and glmM PCR. Real-time PCR was performed on an Applied Biosystems 2720 thermal cycler (Life Technologies, Carlsbad, CA, USA). All the cultured isolates were maintained at $70{ }^{\circ} \mathrm{C}$ in tryptic soy broth (Becton, Dickinson) supplemented with 15\% glycerol (Sigma-Aldrich).

\subsection{Determination of the Minimum Inhibitory Concentration (MIC)}

The susceptibilities of the $H$. pylori isolates were examined by using the agar dilution method. Briefly, the bacteria were subcultured on Mueller-Hinton agar supplemented with $5 \%$ defibrinated sheep blood (Becton, Dickinson) for 48 hours. The bacterial suspension was adjusted to approximately 2.0 McFarland $(1 \times 107$ to $1 \times 108 \mathrm{CFU} / \mathrm{mL})$ and was inoculated directly on each antibiotic-containing agar dilution plate. After incubation for $72 \mathrm{~h}$, the MIC of each antibiotic was determined. The standard strain H. pylori ATCC 43504 was included in the susceptibility testing as a control. The resistance breakpoints for clarithromycin, amoxicillin and metronidazole were defined as $\geq 1.0, \geq 0.5$ and $\geq 8.0$, respectively [21-23].

\subsection{C-Urea Breath Test}

The 13C-urea breath test is recommended to perform for confirmation of $H$. pylori eradication by multiple practical guidelines [6,11,18]. After fasting for at least 4 hours, a breath sample was obtained from the enrolled patients. A tablet containing $100 \mathrm{mg}{ }^{13} \mathrm{C}$ urea (UBIT®tablet; Otsuka Pharmaceutical Co. Ltd., Tokyo, Japan) was administered with $100 \mathrm{~mL}$ of water orally to patients. Then, 20 minutes after taking a tablet, a second breath sample was collected. The presence of $H$. pylori was investigated through the ${ }^{13} \mathrm{C}$-urea- 
urea breath test (Analyzer POCone, Otsuka Electronics Co. Ltd., Osaka, Japan) using the obtained breath samples. The cutoff value used was $2.5 \%$.

\subsection{Statistical Analyses}

All statistical analyses were conducted using SPSS 24.0 for Windows (SPSS Inc., Chicago, IL, USA). Categorical variables were analyzed using the chi-squared test or Fisher's exact test. Continuous variables were analyzed using Student's $t$-test and were reported as the mean with the standard deviation. $P$-values $<0.05$ were considered as statistically significant.

\section{Results}

\subsection{Baseline Characteristics}

The baseline characteristics of the patients are shown in Table 1. There were no statistically significant differences regarding age, sex, and alcohol consumption between the two groups. The overall resistance rates to clarithromycin, amoxicillin, and metronidazole were $24.9 \%, 7.0 \%$, and $34.6 \%$, respectively. Multidrug resistance involving clarithromycin, metronidazole, and amoxicillin was $13.6 \%(35 / 257)$.

Table 1. Clinical characteristics.

\begin{tabular}{|c|c|c|c|c|}
\hline & TOTAL & $\begin{array}{c}\text { Susceptibility-Guided } \\
\text { Therapy }\end{array}$ & Empirical Therapy & $P$-Value \\
\hline Number & 257 & 103 & 154 & \\
\hline Age $($ mean \pm SD) & $58.3 \pm 10.6$ & $57.6 \pm 10.5$ & $58.8 \pm 10.7$ & 0.41 \\
\hline Male $(\%)$ & $147(57.2 \%)$ & $59(57.3 \%)$ & $88(57.1 \%)$ & 0.98 \\
\hline Smoking (\%) & $41(16.0 \%)$ & $17(16.5 \%)$ & $24(15.6 \%)$ & 0.86 \\
\hline Alcohol (\%) & $126(49.0 \%)$ & $49(47.6 \%)$ & $77(50.0 \%)$ & 0.80 \\
\hline Indications & & & & 0.34 \\
\hline Early gastric cancer $(\%)$ & $166(64.6 \%)$ & $69(67.0 \%)$ & $97(63.0 \%)$ & \\
\hline Atrophic gastritis (\%) & $24(9.3 \%)$ & $10(9.7 \%)$ & $14(9.1 \%)$ & \\
\hline MALT lymphoma (\%) & $24(9.3 \%)$ & $7(6.8 \%)$ & $17(11.0 \%)$ & \\
\hline Gastric adenoma $(\%)$ & $19(7.4 \%)$ & $7(6.8 \%)$ & $12(7.8 \%)$ & \\
\hline Peptic ulcer (\%) & $6(2.3 \%)$ & $0(0 \%)$ & $6(3.9 \%)$ & \\
\hline Functional dyspepsia (\%) & $6(2.3 \%)$ & $4(3.9 \%)$ & $2(1.3 \%)$ & \\
\hline Others $(\%)$ & $12(4.7 \%)$ & $5(4.9 \%)$ & $6(3.9 \%)$ & \\
\hline \multicolumn{5}{|l|}{ Resistance } \\
\hline CLR-R (\%) & $63(24.9 \%)$ & $0(0 \%)$ & $64(41.6 \%)$ & $<0.01$ \\
\hline AMX-R (\%) & $18(7.0 \%)$ & $6(5.8 \%)$ & $12(7.8 \%)$ & 0.55 \\
\hline MDZ-R (\%) & $89(34.6 \%)$ & $31(30.1 \%)$ & $58(37.7 \%)$ & 0.21 \\
\hline
\end{tabular}

SD, standard deviation; MALT, mucosa-associated lymphoid tissue; CLR, clarithromycin; AMX, amoxicillin; MDZ, metronidazole; $R$, resistant.

\subsection{Outcomes}

The overall eradication rate was $69.3 \%(178 / 257)$. In the susceptibility-guided therapy group, the eradication rate was $85.4 \%(88 / 103)$, while that in the empirical therapy group was $58.4 \%(90 / 154)$ (Table 2). There was a statistically significant difference regarding the eradication rate between the susceptibility-guided therapy and the empirical therapy groups $(P<0.01)$. TT had a significant difference between the two groups $(85.1 \%$ versus $56.6 \%, P<0.01)$, while SET had a moderate trend toward significance $(86.2 \%$ versus $65.6 \%$, $P=0.06$ ) (Figure 2). 
Table 2. Eradication rates comparing susceptibility-guided therapy with empirical therapy.

\begin{tabular}{|c|c|c|c|c|}
\hline Eradication & TOTAL & Susceptibility-Guided Therapy & Empirical Therapy & $P$-Value \\
\hline Overall $(n=257)$ & & 103 & 154 & \\
\hline Success $(\%)$ & $178(69.3 \%)$ & $88(85.4 \%)$ & $90(58.4 \%)$ & $<0.01$ \\
\hline Failure (\%) & $79(30.7 \%)$ & $15(14.6 \%)$ & $64(41.6 \%)$ & \\
\hline TT $(n=196)$ & & 74 & 122 & \\
\hline Success (\%) & $132(67.3 \%)$ & $63(85.1 \%)$ & $69(56.6 \%)$ & $<0.01$ \\
\hline Failure $(\%)$ & $64(32.7 \%)$ & $11(14.9 \%)$ & $53(43.4 \%)$ & \\
\hline $\operatorname{SET}(n=61)$ & & 29 & 32 & \\
\hline Success (\%) & $46(75.4 \%)$ & $25(86.2 \%)$ & $21(65.6 \%)$ & 0.06 \\
\hline Failure $(\%)$ & $15(24.6 \%)$ & $4(13.8 \%)$ & $11(34.4 \%)$ & \\
\hline
\end{tabular}

TT = triple therapy; SET = sequential therapy.

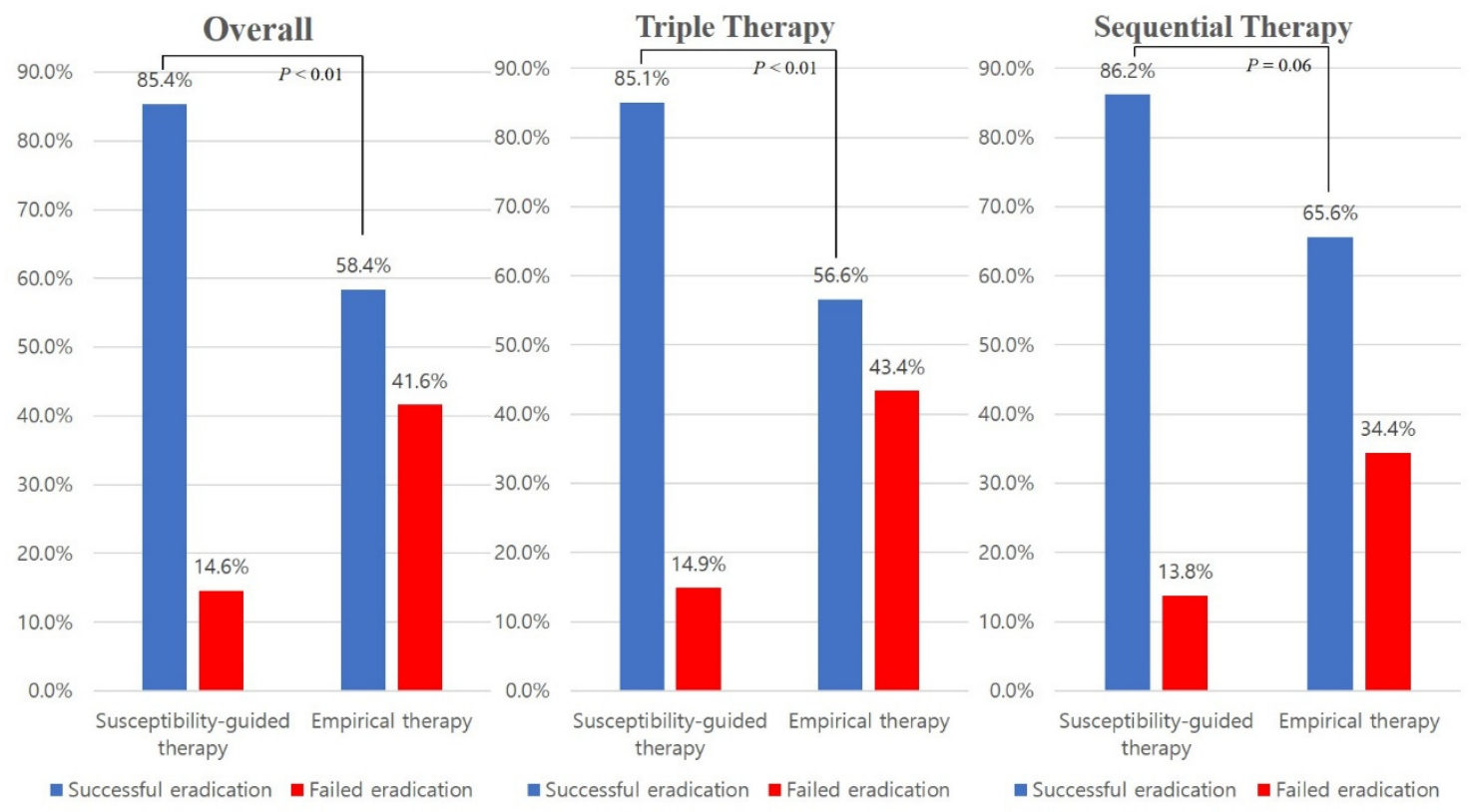

Figure 2. Comparison of the eradication rates between the susceptibility-guided therapy group and the empirical therapy group.

\subsection{Antimicrobial Susceptibility}

According to the antimicrobial susceptibility testing results, TT had an eradication rate of $84.6 \%$, in the case of strains susceptible to both clarithromycin and amoxicillin, and $11.1 \%$ in the case of strains concurrently resistant to both these antimicrobials. SET had an eradication rate of $89.5 \%$ when the strains were susceptible concurrently to clarithromycin, amoxicillin, and metronidazole, whereas it was $0 \%$ when the strains were concurrently resistant to clarithromycin and metronidazole (Table 3). When the strains were susceptible to clarithromycin, the eradication rate was $85.0 \%(164 / 193)$. On the other hand, when the strains were resistant to clarithromycin, the eradication rate was $21.9 \%(14 / 64)$.

TT and SET had eradication rates of $83.9 \%$ and $88.0 \%$, respectively with strains susceptible to clarithromycin $(P=0.49)$, and those of $22.6 \%$ and $18.2 \%$, respectively with strains resistant to clarithromycin $(P>0.99)$ (Appendix A). 
Table 3. Antimicrobial susceptibility testing results.

\begin{tabular}{|c|c|c|c|}
\hline \multicolumn{3}{|c|}{ Antimicrobial Susceptibility Testing in TT } & \multirow{2}{*}{$\begin{array}{c}\text { Number (\%) of Successfu } \\
\text { Eradication }\end{array}$} \\
\hline Clarithromycin & Amoxicillin & & \\
\hline S & S & & $115 / 136(84.6)$ \\
\hline$S$ & $\mathrm{R}$ & & $5 / 7(71.4)$ \\
\hline $\mathrm{R}$ & $S$ & & $11 / 44(25.0)$ \\
\hline $\mathrm{R}$ & $\mathrm{R}$ & & $1 / 9(11.1)$ \\
\hline \multicolumn{3}{|c|}{ Antimicrobial susceptibility testing in SET } & Number (\%) of successful \\
\hline Clarithromycin & Amoxicillin & Metronidazole & eradication \\
\hline S & $S$ & $S$ & $34 / 38(89.5)$ \\
\hline S & S & $\mathrm{R}$ & $8 / 10(80.0)$ \\
\hline$S$ & $\mathrm{R}$ & $\mathrm{S}$ & $1 / 1(100)$ \\
\hline$S$ & $\mathrm{R}$ & $\mathrm{R}$ & $1 / 1(100)$ \\
\hline $\mathrm{R}$ & $\mathrm{S}$ & $\mathrm{S}$ & $2 / 4(50.0)$ \\
\hline $\mathrm{R}$ & $\mathrm{S}$ & $\mathrm{R}$ & $0 / 7(0)$ \\
\hline
\end{tabular}

S, susceptible; R, resistant.

Fifty-three patients were prescribed TT even though their strains were resistant to clarithromycin, with an eradication rate as low as $25.0 \%$ and $11.1 \%$, when they were susceptible and resistant to amoxicillin, respectively. Seven patients whose strains were resistant to both clarithromycin and metronidazole were treated using SET, with an eradication rate of $0 \%$ (Table 4 ). Figure 3 reveals the susceptibility results of each group. In the susceptibilityguided therapy group, 74 patients received TT, and none of their strains were resistant to clarithromycin. The other 29 patients received SET, and none of their strains were resistant to clarithromycin.

Table 4. Antimicrobial susceptibility testing results in the susceptibility and empirical therapy groups.

\begin{tabular}{lc}
\hline \multicolumn{1}{c}{ Antimicrobial Susceptibility } & Eradication Rate \\
\hline Susceptibility-guided therapy group & $n=103$ \\
Triple therapy & $n=74$ \\
CLR-S and AMX-S & $85.5 \%(59 / 69)$ \\
CLR-S and AMX-R & $80.0 \%(4 / 5)$ \\
Sequential therapy & $n=29$ \\
CLR-S and AMX-S and MDZ-S & $87.5 \%(21 / 24)$ \\
CLR-S and AMX-S and MDZ-R & $75.0 \%(3 / 4)$ \\
CLR-S and AMX-R and MDZ-S & $100.0 \%(1 / 1)$ \\
\hline Empirical therapy group & $n=154$ \\
Triple therapy & $n=122$ \\
CLR-S and AMX-S & $83.6 \%(56 / 67)$ \\
CLR-S and AMX-R & $50.0 \%(1 / 2)$ \\
CLR-R and AMX-S & $25.0 \%(11 / 44)$ \\
CLR-R and AMX-R & $11.1 \%(1 / 9)$ \\
Sequential therapy & $n=32$ \\
CLR-S and AMX-S and MDZ-S & $92.9 \%(13 / 14)$ \\
CLR-S and AMX-S and MDZ-R & $83.3 \%(5 / 6)$ \\
CLR-S and AMX-R and MDZ-R & $100 \%(1 / 1)$ \\
CLR-R and AMX-S and MDZ-S & $50.0 \%(2 / 4)$ \\
CLR-R and AMX-S and MDZ-R & $0 \%(0 / 7)$ \\
\hline
\end{tabular}

CLR, clarithromycin; AMX, amoxicillin; MDZ, metronidazole; S, susceptible; R, resistant. 


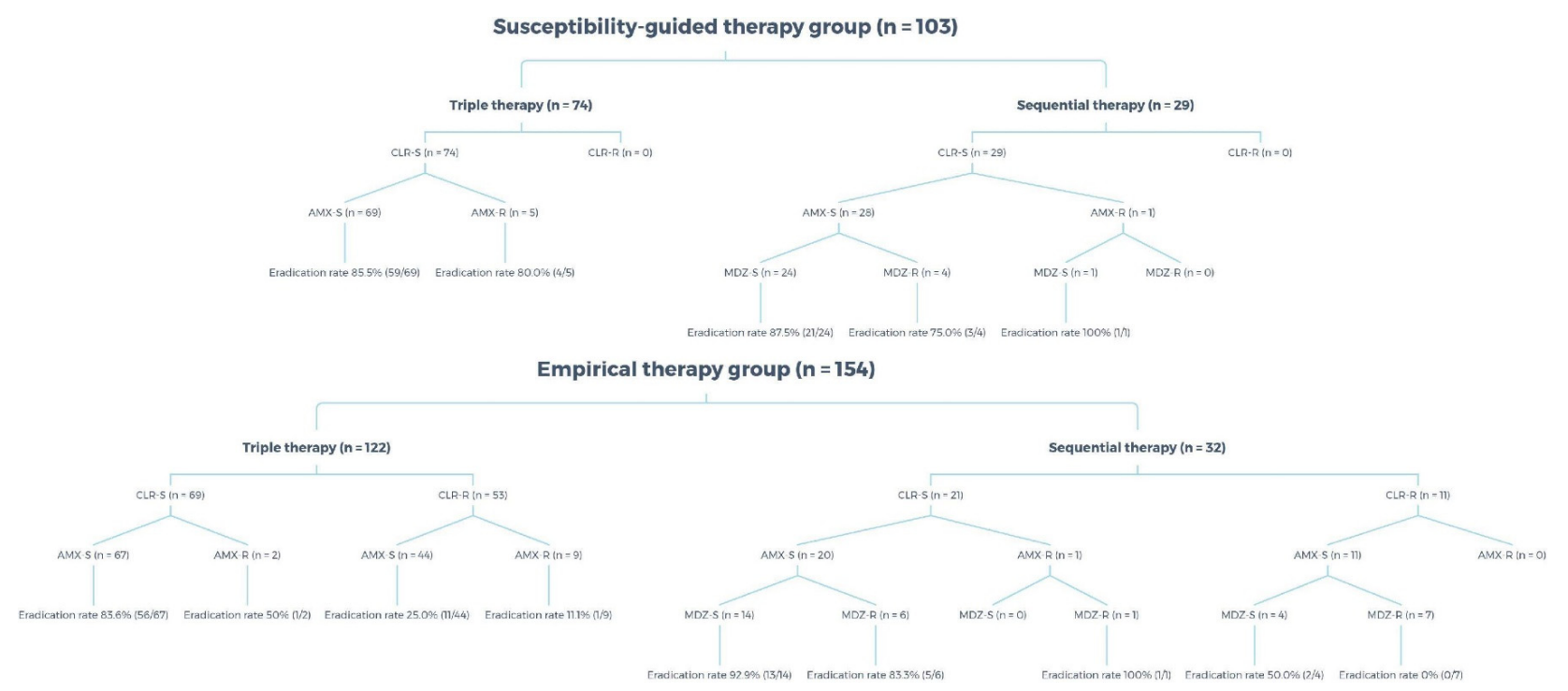

Figure 3. Antimicrobial susceptibility of the susceptibility-guided therapy and the empirical therapy groups. CLR, clarithromycin; AMX, amoxicillin; MDZ, metronidazole; S, susceptible; R, resistant.

\subsection{Second-line Treatment}

Among those who failed to achieve eradication $(n=79), 56$ patients $(70.9 \%)$ started second-line treatment (Table 5). Forty-eight patients received quadruple therapy, five patients were prescribed a regimen composed of a proton pump inhibitor, bismuth, metronidazole, tetracycline, and amoxicillin, and three patients received others. Quadruple therapy as second-line treatment had an eradication rate of $72.9 \%$ in the intention-to-treat analysis and $83.3 \%$ in the per-protocol analysis.

Table 5. Second-line treatment.

\begin{tabular}{cccc}
\hline Treatment & Success & Failure & Loss to Follow-Up \\
\hline Total $(n=56)$ & $40(71.4 \%)$ & $9(16.1 \%)$ & $7(12.5 \%)$ \\
Quadruple $(n=48)$ & $35(72.9 \%)$ & $7(14.6 \%)$ & $6(12.5 \%)$ \\
PBAMT $(n=5)$ & $4(80.0 \%)$ & $1(20.0 \%)$ & 0 \\
Others $(n=3)$ & $1(33.3 \%)$ & $2(66.7 \%)$ & 0 \\
\hline
\end{tabular}

PBAMT, proton pump inhibitor, bismuth, metronidazole, tetracycline, and amoxicillin.

\section{Discussion}

This study aimed to compare susceptibility-guided therapy with empirical therapy as a first-line treatment containing clarithromycin for $H$. pylori eradication and to evaluate the corresponding eradication rates of these regimens according to antimicrobial susceptibility. To the best of our knowledge, this is the largest single-center and is the first study, including sequential therapy comparing susceptibility-guided therapy with empirical therapy for H. pylori eradication. The obtained results documented that the eradication rate of susceptibility-guided therapy was $85.4 \%$ and that of empirical therapy was $58.4 \%$, which showed a significant difference $(P<0.01)$.

TT is used widely as a first-line treatment for $H$. pylori eradication because of the simplicity and cost benefits associated with this regimen. SET was first introduced by Zullo et al. in 2000 as a new regimen for H. pylori eradication [24]. The efficacy of these two regimens, however, has decreased due to increased antibiotic resistance, particularly to clarithromycin [14-17]. The eradication rate with TT varied between the susceptibility-guided therapy and the empirical therapy groups, at $85.1 \%$ and $56.6 \%$, respectively $(P<0.01)$. The eradication rate with SET in the susceptibility-guided therapy group was higher than that in the empirical therapy group with a moderate trend toward significance $(86.2 \%$ versus $65.6 \%, P=0.06)$. Moreover, when $H$. pylori was susceptible to both clarithromycin and 
amoxicillin, TT showed an eradication rate of $84.6 \%$. SET showed an eradication rate of $89.5 \%$ when the strains were susceptible to clarithromycin, amoxicillin, and metronidazole, while it was $0 \%$ in strains concurrently resistant to clarithromycin and metronidazole. The eradication rate with TT was $71.4 \%$ when the strains were susceptible to clarithromycin but resistant to amoxicillin. However, when the strains were resistant to clarithromycin, the eradication rate with TT was as low as $25.0 \%$ (susceptible to amoxicillin) and $11.1 \%$ (resistant to amoxicillin). In addition, the eradication rate with SET was 50.0\% when the strains were resistant to clarithromycin but susceptible to metronidazole. On the other hand, when the strains were resistant to both clarithromycin and metronidazole, the eradication rate with SET was $0 \%$. It was suggested that the eradication rate with TT is influenced mostly by clarithromycin resistance but that SET is affected not only by clarithromycin resistance but also by metronidazole resistance. Other studies indicated that clarithromycin resistance has a lesser influence on the efficacy of SET than that of TT $[25,26]$.

The resistance rate to clarithromycin, amoxicillin, and metronidazole in this study was $24.9 \%, 7.0 \%$ and $34.6 \%$, respectively, which were in accordance with the resistance rates in Korea as reported previously $[27,28]$. Thirty-five patients showed multidrug resistance involving those three antibiotics $(35 / 257,13.6 \%)$, which was in accordance with the previously reported data in Korea as $11.2 \%$ [28]. There is no treatment consensus for multidrug-resistant $H$. pylori treatment, and antimicrobial susceptibility testing is increasingly important [29]. In the empirical therapy group, the clarithromycin resistance rate was $41.6 \%$. This high resistance rate could be explained by the increasing resistance rates in Korea, from $43.7 \%$ in 2015-2016 to 45.9\% in 2017-2018, as reported by Lee et al. [27], because in this study, most patients of the empirical therapy group underwent antimicrobial susceptibility tests from 2015-2018 (135 of 154). In addition, this study revealed that the eradication rates with TT and SET were $67.3 \%$ and $75.4 \%$, respectively, similar to previously assumed eradication rates [30].

When the strains were susceptible to both clarithromycin and amoxicillin, TT showed an eradication rate of $85.5 \%$ in the susceptibility-guided therapy group and $83.6 \%$ in the empirical therapy group, both of which were lower than $90 \%$. Lower-than-expected eradication rates could be explained by the patients' poor compliance with the treatment [31,32] and antimicrobial heteroresistance, defined as the presence of heterogeneous populations of co-existing bacteria that have different levels of antibiotic resistance from one another [33]. Lee et al. reported that approximately $10 \%$ of patients failed to take eradication therapy medications [34]. Unfortunately, due to a lack of medical records, we could not investigate the treatment compliance of the participants in this study. Matteo et al. documented that two H. pylori strain obtained from one person's gastric mucosa significantly differed in antimicrobial susceptibility [35]. In this study, however, we could not investigate the biopsy sites and the number of obtained biopsies due to a lack of medical records. Moreover, in TT, a low proportion of 14-day treatment duration rather than 7-day treatment duration may explain the lower eradication rate. Among those, who received TT in the susceptibilityguided therapy group, the 14-day treatment regimen was administered only to $10.8 \%$ of the patients $(8 / 66)$, whose eradication rate was $100 \%$. However, the eradication rates were not statistically significant differences between the 7- and 14-day treatment duration. Similarly, strains susceptible to all the three antibiotics had an eradication rate with SET at $87.5 \%$ and $92.9 \%$ in the susceptibility-guided therapy and the empirical therapy groups, respectively, which were not $100 \%$.

Among the 56 patients, who started second-line treatment after failing the firstline treatment, 49 received quadruple therapy, as suggested by multiple practical guidelines $[6,11,18]$. The results showed that the eradication rate with second-line quadruple therapy was $83.3 \%$, which was in accordance with the nationwide $H$. pylori registry study in Korea [36]. After the failure of second-line treatment, there is no treatment consensus. Levofloxacin triple regimen or rifabutin triple regimen is suggested as rescue therapy by the guidelines $[6,18]$. However, Lim et al. reported in 2017 that the eradication rate of levofloxacin triple regimen as third-line treatment was 56.9\% in Korea [37]. This low eradication 
rate can be explained by the high-resistance rate to levofloxacin in Korea [28,38]. Rifabutin triple regimen has several limitations. First, this drug is expensive. Second, myelotoxicity causing severe leukopenia or thrombocytopenia has been reported. Finally, there is an opinion that the use of rifabutin should be reserved for Mycobacterium tuberculosis because multidrug-resistant $M$. tuberculosis has increased [39]. More efforts and studies regarding rescue therapy after the failure of second-line therapy are required.

From this study, amoxicillin was found to play a less decisive role in TT. The eradication rate of the amoxicillin-susceptible strains with TT was not much different from that of amoxicillin-resistant strains when the strains were clarithromycin-susceptible $(84.6 \%$ vs. $71.4 \%, P=0.36)$. Metronidazole was also found to play an important role in SET. The eradication rate of SET was $0 \%$ when the strains were resistant to both clarithromycin and metronidazole in the empirical therapy group.

There are several limitations to this study. First, this is a retrospective, observational, single-center study, so it may limit generalizing the results. Second, the compliance of the participants and the adverse reactions related to $H$. pylori eradication therapy were not investigated. Compliance with therapy is accepted as the single most important factor in $H$. pylori eradication, while a major cause of poor compliance is the presence of adverse reactions. Third, the biopsy sites and the number of obtained biopsies were not investigated. Thus, antimicrobial heteroresistance, which is a risk factor for lower-than-expected eradication rates, was not examined. Lastly, empirical therapy was performed more frequently despite susceptibility testing being carried out. Failure of H. pylori culture is not common $[19,20]$, and it takes more than 10 days, sometimes as long as two weeks, to obtain the results of susceptibility testing [21]. More than half of the participants came to the outpatient clinics before the susceptibility testing results were reported, and a majority of them wanted to start $H$. pylori eradication therapy as soon as possible. Because multiple practical guidelines recommend empirical therapy as first-line treatment for $H$. pylori, there were no medical issues regarding the provision of this regimen.

In conclusion, susceptibility-guided therapy based on antimicrobial susceptibility tests as clarithromycin-containing first-line treatment for $H$. pylori improved the eradication rate of TT and SET by $28.5(P<0.01)$ and $20.6(P=0.06)$ percent points, respectively, compared with empirical therapy.

Author Contributions: S.K. and Y.K. contributed equally as first authors. Conceptualization, data curation, formal analysis, investigation, and writing—original draft preparation, S.K. and Y.K.; formal analysis, N.K.; conceptualization, data curation, methodology, supervision, and writing-review and editing, J.Y.A. and H.-Y.J.; data curation and supervision, H.K.N., J.H.L., K.W.J., D.H.K., K.D.C., H.J.S., G.H.L. All authors have read and agreed to the published version of the manuscript.

Funding: This research received no external funding.

Institutional Review Board Statement: The study was conducted according to the guidelines of the Declaration of Helsinki and approved by the Institutional Review Board of the Asan Medical Center (IRB number; 2020-0518).

Informed Consent Statement: Patient consent was waived due to this being a retrospective study.

Data Availability Statement: The data presented in this study are available on request from the corresponding author. The data are not publicly available due to privacy.

Conflicts of Interest: The authors declare no conflict of interest. 


\section{Appendix A}

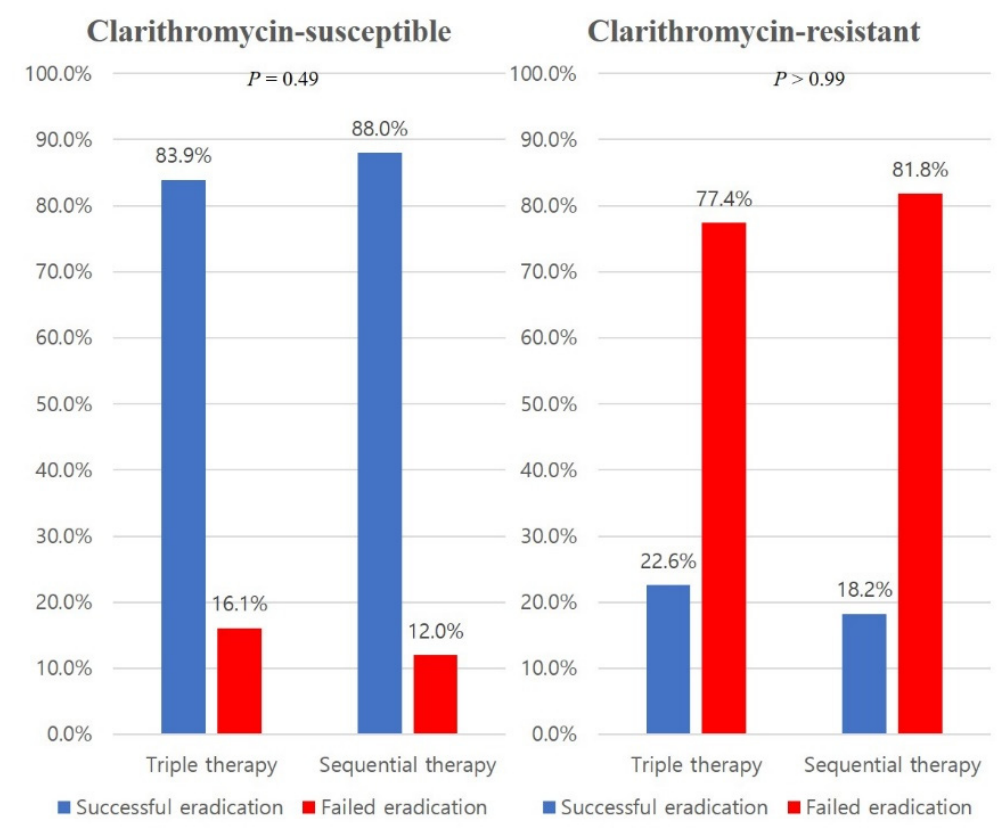

Figure A1. Comparison of the eradication rates between triple therapy and sequential therapy according to clarithromycin susceptibility.

\section{References}

1. Hooi, J.K.Y.; Lai, W.Y.; Ng, W.K.; Suen, M.M.Y.; Underwood, F.E.; Tanyingoh, D.; Malfertheiner, P.; Graham, D.Y.; Wong, V.W.S.; $\mathrm{Wu}$, J.C.Y.; et al. Global prevalence of Helicobacter pylori infection: Systematic review and meta-analysis. Gastroenterology 2017, 153, 420-429. [CrossRef]

2. Lee, J.H.; Choi, K.D.; Jung, H.Y.; Baik, G.H.; Park, J.K.; Kim, S.S.; Kim, B.W.; Hong, S.J.; Lim, H.; Shin, C.M.; et al. Seroprevalence of Helicobacter pylori in Korea: A multicenter, nationwide study conducted in 2015 and 2016. Helicobacter 2018, 23, e12463. [CrossRef]

3. McColl, K.E. Clinical practice. Helicobacter pylori infection. N. Engl. J. Med. 2010, 362, 1597-1604. [CrossRef]

4. Lim, J.H.; Kim, N.; Lim, S.H.; Kwon, J.W.; Shin, C.M.; Chang, Y.S.; Kim, J.S.; Jung, H.C.; Cho, S.H. Inverse relationship between Helicobacter pylori infection and asthma among adults younger than 40 years: A cross-sectional study. Medicine (Baltim.) 2016, 95, e2609. [CrossRef] [PubMed]

5. de Korwin, J.D.; Ianiro, G.; Gibiino, G.; Gasbarrini, A. Helicobacter pylori infection and extragastric diseases in 2017. Helicobacter 2017, 22, e12411. [CrossRef] [PubMed]

6. Chey, W.D.; Leontiadis, G.I.; Howden, C.W.; Moss, S.F. ACG clinical guideline: Treatment of Helicobacter pylori infection. Am. J. Gastroenterol. 2017, 112, 212-239. [CrossRef]

7. Scott, D.; Weeks, D.; Melchers, K.; Sachs, G. The life and death of Helicobacter pylori. Gut 1998, 43, S56-S60. [CrossRef]

8. Mizoguchi, H.; Fujioka, T.; Nasu, M. Evidence for viability of coccoid forms of Helicobacter pylori. J. Gastroenterol. 1999, 34, 32-36.

9. Graham, D.Y.; Shiotani, A. New concepts of resistance in the treatment of Helicobacter pylori infections. Nat. Clin. Pract. Gastroenterol. Hepatol. 2008, 5, 321-331. [CrossRef]

10. Ierardi, E.; Losurdo, G.; Fortezza, R.F.L.; Principi, M.; Barone, M.; Leo, A.D. Optimizing proton pump inhibitors in Helicobacter pylori treatment: Old and new tricks to improve effectiveness. World J. Gastroenterol. 2019, 25, 5097-5104. [CrossRef]

11. Kim, S.G.; Jung, H.K.; Lee, H.L.; Jang, J.Y.; Lee, H.; Kim, C.G.; Shin, W.G.; Shin, E.S.; Lee, Y.C.; Korean College of Helicobacter and Upper Gastrointestinal Research; et al. Guidelines for the diagnosis and treatment of Helicobacter pylori infection in Korea, 2013 revised edition. Korean J. Gastroenterol. 2013, 62, 3-26. [CrossRef]

12. Leung, W.K.; Graham, D.Y. Clarithromycin for Helicobacter pylori infection. Expert Opin. Pharmacother. 2000, 1, 507-514. [CrossRef]

13. Peterson, W.L.; Graham, D.Y.; Marshall, B.; Blaser, M.J.; Genta, R.M.; Klein, P.D.; Stratton, C.W.; Drnec, J.; Prokocimer, P.; Siepman, N. Clarithromycin as monotherapy for eradication of Helicobacter pylori: A randomized, double-blind trial. Am. J. Gastroenterol. 1993, 88, 1860-1864.

14. Bang, C.S.; Baik, G.H. Attempts to enhance the eradication rate of Helicobacter pylori infection. World J. Gastroenterol. 2014, $20,5252-5262$. [CrossRef]

15. Kim, S.Y.; Choi, D.J.; Chung, J.W. Antibiotic treatment for Helicobacter pylori: Is the end coming? World J. Gastrointest. Pharmacol. Ther. 2015, 6, 183-198. [CrossRef] 
16. Shin, W.G.; Lee, S.W.; Baik, G.H.; Huh, K.C.; Lee, S.I.; Chung, J.W.; Jung, W.T.; Park, M.I.; Jung, H.K.; Kim, H.U.; et al. Eradication rates of Helicobacter pylori in Korea over the past 10 years and correlation of the amount of antibiotics use: Nationwide survey. Helicobacter 2016, 21, 266-278. [CrossRef] [PubMed]

17. Hwang, T.J.; Kim, N.; Kim, H.B.; Lee, B.H.; Nam, R.H.; Park, J.H.; Lee, M.K.; Park, Y.S.; Lee, D.H.; Jung, H.C.; et al. Change in antibiotic resistance of Helicobacter pylori strains and the effect of A2143G point mutation of $23 \mathrm{~S}$ rRNA on the eradication of H. pylori in a single center of Korea. J. Clin. Gastroenterol. 2010, 44, 536-543. [CrossRef] [PubMed]

18. Malfertheiner, P.; Megraud, F.; O’Morain, C.A.; Gisbert, J.P.; Kuipers, E.J.; Axon, A.T.; Bazzoli, F.; Gasbarrini, A.; Atherton, J.; Graham, D.Y.; et al. Management of Helicobacter pylori infection-the Maastricht V/Florence Consensus Report. Gut 2017, 66, 6-30. [CrossRef]

19. Kjoller, M.; Fischer, A.; Justesen, T. Transport conditions and number of biopsies necessary for culture of Helicobacter pylori. Eur. J. Clin. Microbiol. Infect. Dis. 1991, 10, 166-167. [CrossRef]

20. Cammarota, G.; Ianiro, G.; Bibbo, S.; Di Rienzo, T.A.; Masucci, L.; Sanguinetti, M.; Gasbarrini, A. Culture-guided treatment approach for Helicobacter pylori infection: Review of the literature. World J. Gastroenterol. 2014, 20, 5205-5211. [CrossRef]

21. Clinical and Laboratory Standards Institute (CLSI). Methods for Antimicrobial Dilution and Disk Susceptibility Testing of Infrequently Isolated or Fastidious Bacteria, 3rd ed.; CLSI Guideline M45; CLSI: Wayne, PA, USA, 2015.

22. Kim, J.M.; Kim, J.S.; Jung, H.C.; Kim, N.; Song, I.S. Antibiotic resistance of Helicobacter pylori isolated from Korean patients in 2003. Korean J. Gastroenterol. 2004, 44, 126-135.

23. Kim, J.M.; Kim, J.S.; Jung, H.C.; Kim, N.; Kim, Y.J.; Song, I.S. Distribution of antibiotic MICs for Helicobacter pylori strains over a 16-year period in patients from Seoul, South Korea. Antimicrob. Agents Chemother. 2004, 48, 4843-4847. [CrossRef]

24. Zullo, A.; Rinaldi, V.; Winn, S.; Meddi, P.; Lionetti, R.; Hassan, C.; Ripani, C.; Tomaselli, G.; Attili, A.F. A new highly effective short-term therapy schedule for Helicobacter pylori eradication. Aliment. Pharmacol. Ther. 2000, 14, 715-718. [CrossRef]

25. Liou, J.M.; Chen, C.C.; Chen, M.J.; Chen, C.C.; Chang, C.Y.; Fang, Y.J.; Lee, J.Y.; Hsu, S.J.; Luo, J.C.; Chang, W.H.; et al. Sequential versus triple therapy for the first-line treatment of Helicobacter pylori: A multicentre, open-label, randomised trial. Lancet 2013, 381, 205-213. [CrossRef]

26. Gatta, L.; Scarpignato, C.; Fiorini, G.; Belsey, J.; Saracino, I.M.; Ricci, C.; Vaira, D. Impact of primary antibiotic resistance on the effectiveness of sequential therapy for Helicobacter pylori infection: Lessons from a 5-year study on a large number of strains. Aliment. Pharmacol. Ther. 2018, 47, 1261-1269. [CrossRef] [PubMed]

27. Lee, J.Y.; Kim, N.; Nam, R.H.; In Choi, S.; Lee, J.W.; Lee, D.H. Primary and secondary antibiotic resistance of Helicobacter pylori in Korea from 2003 to 2018. Helicobacter 2019, 24, e12660. [CrossRef] [PubMed]

28. Lee, J.H.; Ahn, J.Y.; Choi, K.D.; Jung, H.Y.; Kim, J.M.; Baik, G.H.; Kim, B.W.; Park, J.C.; Jung, H.K.; Cho, S.J.; et al. Nationwide antibiotic resistance mapping of Helicobacter pylori in Korea: A prospective multicenter study. Helicobacter 2019, 24, e12592. [CrossRef]

29. Boyanova, L.; Hadzhiyski, P.; Kandilarov, N.; Markovska, R.; Mitov, I. Multidrug resistance in Helicobacter pylori: Current state and future directions. Expert Rev. Clin. Pharmacol. 2019, 12, 909-915. [CrossRef]

30. Kim, J.S.; Kim, B.W.; Ham, J.H.; Park, H.W.; Kim, Y.K.; Lee, M.Y.; Ji, J.S.; Lee, B.I.; Choi, H. Sequential therapy for Helicobacter pylori infection in korea: Systematic review and meta-analysis. Gut Liver 2013, 7, 546-551. [CrossRef]

31. O'Connor, J.P.; Taneike, I.; O'Morain, C. Improving compliance with Helicobacter pylori eradication therapy: When and how? Therap. Adv. Gastroenterol. 2009, 2, 273-279. [CrossRef]

32. Jaka, H.; Mueller, A.; Kasang, C.; Mshana, S.E. Predictors of triple therapy treatment failure among H. pylori infected patients attending at a tertiary hospital in Northwest Tanzania: A prospective study. BMC Infect. Dis. 2019, 19, 447. [CrossRef]

33. El-Halfawy, O.M.; Valvano, M.A. Antimicrobial heteroresistance: An emerging field in need of clarity. Clin. Microbiol. Rev. 2015, 28, 191-207. [CrossRef]

34. Lee, M.; Kemp, J.A.; Canning, A.; Egan, C.; Tataronis, G.; Farraye, F.A. A randomized controlled trial of an enhanced patient compliance program for Helicobacter pylori therapy. Arch. Intern. Med. 1999, 159, 2312-2316. [CrossRef]

35. Matteo, M.J.; Granados, G.; Olmos, M.; Wonaga, A.; Catalano, M. Helicobacter pylori amoxicillin heteroresistance due to point mutations in PBP-1A in isogenic isolates. J. Antimicrob. Chemother. 2008, 61, 474-477. [CrossRef]

36. Kim, B.J.; Yang, C.H.; Song, H.J.; Jeon, S.W.; Kim, G.H.; Kim, H.S.; Kim, T.H.; Shim, K.N.; Chung, I.K.; Park, M.I.; et al. Online registry for nationwide database of Helicobacter pylori eradication in Korea: Correlation of antibiotic use density with eradication success. Helicobacter 2019, 24, e12646. [CrossRef] [PubMed]

37. Lim, J.H.; Kim, S.G.; Song, J.H.; Hwang, J.J.; Lee, D.H.; Han, J.P.; Hong, S.J.; Kim, J.H.; Jeon, S.W.; Kim, G.H.; et al. Efficacy of levofloxacin-based third-line therapy for the eradication of Helicobacter pylori in peptic ulcer disease. Gut Liver 2017, 11, 226-231. [CrossRef]

38. An, B.; Moon, B.S.; Kim, H.; Lim, H.C.; Lee, Y.C.; Lee, G.; Kim, S.H.; Park, M.; Kim, J.B. Antibiotic resistance in Helicobacter pylori strains and its effect on H. pylori eradication rates in a single center in Korea. Ann. Lab. Med. 2013, 33, 415-419. [CrossRef]

39. Gisbert, J.P.; Calvet, X. Review article: Rifabutin in the treatment of refractory Helicobacter pylori infection. Aliment. Pharmacol. Ther. 2012, 35, 209-221. [CrossRef] 